\title{
Human adipose tissue-derived mesenchymal stem cells in rheumatoid arthritis: Regulatory effects on peripheral blood mononuclear cells activation
}

\author{
Rasoul Baharlou ${ }^{\text {a }}$, Abbas Ahmadi-Vasmehjani ${ }^{\text {a,* }}$, Fatemeh Faraji ${ }^{\text {a }}$, Mohammad Reza Atashzar ${ }^{\text {a }}$ \\ Mahshid Khoubyari ${ }^{\mathrm{b}}$, Salma Ahi ${ }^{\mathrm{c}}$, Saiedeh Erfanian ${ }^{\mathrm{d}}$, Shadi-Sadat Navabi ${ }^{\mathrm{a}}$ \\ a Department of Immunology and Microbiology, School of Medicine, Jahrom University of Medical Sciences, Jahrom, Iran \\ b Department of Student Research Committee, School of Medicine, Jahrom University of Medical Sciences, Jahrom, Iran \\ c Department of Internal Medicine, School of Medicine, Jahrom University of Medical Sciences, Jahrom, Iran \\ d Research Center for Non-Communicable Diseases, School of Medicine, Jahrom University of Medical Sciences, Jahrom, Iran
}

\section{A R T I C L E I N F O}

\section{Article history:}

Received 7 January 2017

Received in revised form 11 March 2017

Accepted 13 March 2017

Available online $\mathrm{xxxx}$

\section{Keywords:}

Adipose tissue-derived mesenchymal stem cells

Peripheral blood mononuclear cells

Rheumatoid arthritis

T helper 17 cells

Inflammation

\begin{abstract}
A B S T R A C T
Background and objectives: Mesenchymal stem cells (MSCs) are multipotent adult stem cells with immunomodulatory properties. The mechanisms by which MSCs inhibit the proliferation of pro-inflammatory T cells have not been fully elucidated yet. It is assumed that pro-inflammatory T-cells play an important role in the development of autoimmune diseases. We investigated the potential therapeutic effects of human adipose tissue derived (Ad)MSCs on the peripheral blood mononuclear cells (PBMCs) of rheumatoid arthritis (RA) patients and healthy individuals, with a particular focus on Th17-associated cytokines.

Materials and methods: PBMCs from RA patients and healthy donors were co-cultured with Ad-MSCs and HeLa with or without Phytohemagglutinin (PHA). Finally, IL-6, IL-17, IL-21, IL-23 and TGF- $\beta$ levels were determined by ELISA and quantitative real-time RT-PCR on co-culture supernatants and PBMCs, respectively.

Results: In co-culture interaction, Ad-MSCs inhibited IL-17 secretion by PBMCs compared to unstimulated PBMCs cultured alone. In addition, IL-21 expressions in PBMCs of the patient group, and IL-17 and IL-21 in healthy group were inhibited by Ad-MSCs compared to PBMCs cultured alone. TGF- $\beta$ expression in healthy individuals remarkably increased in both MSC-treated groups with and without PHA in comparison to PHA-stimulated and -unstimulated PBMCs.

Conclusions: This study demonstrates that human Ad-MSCs act as key regulators of immune tolerance by inhibiting the inflammation. Therefore, they can be attractive candidates for immunomodulatory cell-based therapy in RA.
\end{abstract}

(C) 2017 Published by Elsevier B.V.

\section{Introduction}

Mesenchymal stem cells (MSCs) are multipotent stromal cells characterized by their ability to differentiate into adipocytes, chondrocytes, osteoblasts and others, which makes them an interesting cell source for application in regenerative medicine [1]. Another important characteristic of MSCs is their immunoregulatory capacity to inhibit the proliferation of T and B lymphocytes, natural killer, and dendritic cells both in vitro and in vivo [2-4]. Interestingly, they can be induced in an inflammatory condition to exert immunoregulatory effects. MSCs inhibit proliferation and function of $\mathrm{CD}^{+}$and $\mathrm{CD}^{+} \mathrm{T}$ cells. They suppress

* Corresponding author at: Department of Immunology and Microbiology, Jahrom University of Medical Sciences, School of Medicine, Motahari Blvd, Jahrom, Iran.

E-mail address: ahvasmehjani@gmail.com (A. Ahmadi-Vasmehjani). production of interleukin (IL)-2 and tumor necrosis factors-alpha (TNF- $\alpha$ ) by the similar cells, and induce differentiation and function of Treg cells by producing some regulatory molecules such as transforming growth factor-beta (TGF- $\beta$ ), prostaglandin E2 (PGE2), IL-10, and indolamine 2,3-dioxygenase (IDO) [5-8].

In the light of the immune-suppressive functions of MSCs, they have been considered as a therapeutic modality for treatment of various autoimmune diseases, such as multiple sclerosis, systemic lupus erythematosus, and others [9]. One of the targets of MSCs therapy is rheumatoid arthritis (RA).

RA is a chronic and systemic disease that primarily attacks synovial joints, leads to articular destruction and functional disability [10]. In RA, pro-inflammatory cytokines such as TNF-a, IL-6, IL-1, and IL-17 play dominant pathological roles. In the context of inflammatory diseases such as RA, T helper 1 (Th1) and Th17 subsets are well known 
to mediate inflammation [11-13]. Furthermore, evidence is being accumulated that a defect in number or function of Tregs is important in the immune imbalance that culminates in RA $[14,15]$.

Efforts to discover new target therapies for RA have achieved considerable success. For instance, TNF- $\alpha$ inhibitors and B-cell-depleting therapies have benefited many RA patients $[16,17]$. However, these approaches are expensive and none of them reach long-term drugfree remission $[18,19]$. Therefore, it is important to develop a new and more effective therapy for RA treatment. In this regard, new effective therapeutic approaches for RA treatment such as the use of MSCs has been considered by many researchers.

In fact, the use of various-sourced MSCs in a collagen-induced arthritis (CIA) model has brought promising results. Zhou et al. demonstrated preventive and therapeutic effects of human adipose tissue-derived MSCs (hAd-MSCs) administered before or during the early phase of arthritis induction [20].

In the same line, Maccario et al. demonstrated that MSCs favor the differentiation of $\mathrm{CD} 4^{+} \mathrm{T}$ cell subsets co-expressing $\mathrm{CD} 25$ and/or cytotoxic T-lymphocyte-associated protein 4 (CTLA4), two markers of Treg cells [21]. These observations were supported and extended by a study showing that direct MSC-T cell contact is required for Foxp3 and CD25 $5^{\text {High }}$ expression by $\mathrm{CD} 4^{+} \mathrm{T}$ cells. Liu et al. reported that MSCs have a suppressive effect on the proliferation, invasive behavior and inflammatory responses of fibroblast-like synoviocytes (FLSs) from RA patients. Their study also demonstrated that MSCs could inhibit activation of T cells and induce Tregs expansion in RA [22]. Another study on synovial fluid (SF)-MSCs showed that the immunosuppressive properties of these MSCs in CIA mice were associated with increased levels of the anti-inflammatory cytokine IL-10, and decreased levels of the proinflammatory cytokine IL-1 $\beta$ [23].

Therefore, in present study, we explored the capacity of Ad-MSCs to inhibit PBMCs in RA patients and healthy individuals. The aim of this study was to determine whether Ad-MSCs are able to reduce the Th17-associated cytokines in vitro when co-cultured with PBMCs, via the assessment of pro-inflammatory and anti-inflammatory cytokines including IL-6, IL-17, IL-21, IL-23, and TGF- $\beta$.

\section{Materials and methods}

\subsection{Isolation and culture of Ad-MSCS}

Ten adipose tissues were obtained from 10 Iranian normal women with mean age of 31 years, related to the Department of Obstetrics \& Gynecology at Motahari and Peymanieh hospitals of Jahrom University of Medical Sciences. Ad-MSCs were isolated from 7 adipose tissues. All samples were used after giving consent and also, the current study was approved by Ethical Committee of Jahrom University of Medical Sciences. Briefly, the tissue slices were cultured in DMEM $+10 \%$ FBS (Gibco) and $1 \%$ penicillin/streptomycin (Biosera) at $37{ }^{\circ} \mathrm{C}$ with $5 \% \mathrm{CO}_{2}$ and $95 \%$ humidity. Non-adherent cells were discarded after culture for 24 h. After 5-7 days, migrated spindle-shaped MSCs were found on the bottom of culture flask. Cells were passaged once $80 \%$ confluence was achieved. The third generation of MSCs was detached by $0.25 \%$ trypsin, followed by the addition of $10 \%$ FBS 1 min later. The cells were centrifuged at $300 \times g$ for 5 min to remove the supernatant. In order to confirm whether the fat-derived cells were indeed Ad-MSCs or not, they were characterized by flow cytometry. In addition, HeLa cells (negative control cell line) were gifted from Shiraz Institute for Cancer Research (Shiraz University of Medical Sciences) and were cultivated in accordance with Ad-MSCs.

\subsection{Subjects}

Fourteen RA patients with mean age of $47 \pm 12$ years ( 13 females and 1 male), that confirmed using American College of Rheumatology (ACR) diagnostic criteria by an internist using simple sampling, were
Table 1

Clinical status of patients with rheumatoid arthritis.

\begin{tabular}{ll}
\hline Variables & State \\
\hline Gender & \\
Male & $7 \%$ \\
Female & $93 \%$ \\
Age \pm SD & $47 \pm 12$ \\
Disease duration (years) & $10.4(5-16)$ \\
RF, positive & $81 \%$ \\
CRP, positive & $83 \%$ \\
ESR, high & $66 \%$ \\
Anti-CCP, positive & $57 \%$ \\
Treatment & \\
MTX & $28 \%$ \\
SSZ & $64 \%$ \\
Prednisolone & $50 \%$ \\
\hline
\end{tabular}

RF: Rheumatoid factor; CRP: C-reactive protein; ESR: Erythrocyte sedimentation rate; Anti-CCP: Anti-cyclic citrullinated peptide; MTX: methotrexate; SSZ: sulfasalazine.

selected from Motahari Hospital of Jahrom University of Medical Sciences. The study was approved by Jahrom University of Medical Sciences Ethics Committee, and informed consent was obtained from patients. RA patients with other chronic diseases, e.g. malignancies, coronary heart disease, thyroid disease, and also infectious disease were excluded from this study. Table 1 demonstrates the clinical status of RA patients. Blood samples from 11 healthy females with mean age of $36 \pm 5$ years without a history of malignancies or autoimmune disorders were also obtained as the control group. During sample collection, it was ensured that subjects had neither infection nor any acute or chronic disease. Peripheral venous blood samples $(10 \mathrm{~mL})$ were collected by venipuncture before any clinical intervention and prepared for isolation of PBMCs.

\subsection{Isolation of PBMCs and serum separation}

PBMCs were obtained from buffy coats of donated blood samples supplemented with anticoagulants. Briefly, samples carefully were run over $5 \mathrm{~mL}$ Ficoll (LymphodexInno, Germany) in a $15 \mathrm{~mL}$ conical tube. Samples were centrifuged at $400 \times \mathrm{g}$ for $40 \mathrm{~min}$ at $20{ }^{\circ} \mathrm{C}$ without a break. The mononuclear cell layer was transferred to a new $15 \mathrm{~mL}$ tube and washed with PBS at $300 \times \mathrm{g}$ for $10 \mathrm{~min}$ at $20^{\circ} \mathrm{C}$. The cell pellet was re-suspended in $50 \mathrm{~mL}$ of PBS and centrifuged at $200 \times \mathrm{g}$ for $15 \mathrm{~min}$ at $20^{\circ} \mathrm{C}$ in order to remove platelets. In addition, $2 \mathrm{~mL}$ peripheral blood was collected for serum separation. Finally, the serum samples were stored at $-70{ }^{\circ} \mathrm{C}$ until cytokine measurement.

\subsection{Flow cytometry}

For flow cytometry analysis, Ad-MSCs were harvested using dissociation solution (Sigma, USA). For Ad-MSCs immunophenotyping, harvested cells $\left(5 \times 10^{6}\right)$ were washed twice with PBS and stained with phycoerythrin (PE)-conjugated mouse anti-human CD44, CD105 and CD166 (BD Biosciences, USA) and fluorescein isothiocyanate (FITC)conjugated mouse anti-human CD14, CD34 and CD45 (BD Biosciences, USA) antibodies. Also, cells were stained with FITC- or PE-labeled mouse immunoglobulin G (BD Biosciences, USA) as negative controls. After 30 min incubation at room temperature, cells were washed twice with PBS. Approximately, $10^{4}$ events were collected on a four colors Becton Dickinson FACS Vantage instrument and further analyzed using WINMDI software version 2.8 (Scripps Research Institute, La Jolla, CA, USA).

\subsection{Co-culture of PBMCS and Ad-MSCS}

MSCs-PBMCs co-cultures were established in different stimulation regimens in DMEM $+10 \%$ FBS + antibiotics. Seven experimental groups 
Table 2

Forward and reverse primers of GAPDH, IL-6, IL-17, IL-21, IL-23, and TGF- $\beta$ genes for realtime PCR amplification. Sequences were designed by Primer3 software (Source forge, USA).

\begin{tabular}{ll}
\hline Primers & Sequence \\
\hline GAPDH forward & 5' TCGGAGTCAACGGATTTGGTC 3' \\
GAPDH reverse & 5' GCCATGGGTGGAATCATATTGG 3' \\
IL-6 forward & 5' CAG GTT GTT TTC TGC CAG TG 3' \\
IL-6 reverse & 5' GAC CGA CAC TCA CCT CTT CA 3' \\
IL-17 forward & 5' GGA CTG TGA TGG TCA ACC TG 3' \\
IL-17 reverse & 5' CTC CCA GAT CAC AGA GGG AT 3' \\
IL-21 forward & 5' AGG TCA AGA TCG CCA CAT 3' \\
IL-21 reverse & 5' TTT GCT GAC TTT AGT TGG GC 3' \\
IL-23 forward & 5' CAA GTG GAA GTG GGC AGA G 3' \\
IL-23 reverse & 5' CAG CAA CAG CAG CAT TAC AG 3' \\
TGF- $\beta$ forward & 5' AAC GAA CTG GCT GTC TGC3' \\
TGF- $\beta$ reverse & 5' CCT CTG CTC ATT CCG CTT AG 3' \\
\hline
\end{tabular}

were considered for both patient and healthy individuals: the main groups involving Ad-MSCs, PBMCs and PHA; Ad-MSCs with unstimulated PBMCs to eliminate PHA effects; positive control group with HeLa, PBMCs and PHA to eliminate co-culture effects and 4 negative control groups including: 1) PBMCs alone with PHA, 2) PBMCs alone without PHA, 3) Ad-MSCs and 4) HeLa alone. Both last groups were used to eliminate adhesive cell effects in supernatant. To identify the MSCs effect on PBMCs, groups which contain PBMCs were compared to groups with PHA stimulated and unstimulated PBMCs. To eliminate co-culture effect, main group was compared with positive control group with HeLa. First, Ad-MSCs and HeLa with a cell density of $10^{5} /$ $\mathrm{mL}$ was imbedded in a 12-well plate, in order to adhere to plastic wells, which was followed by addition of $10^{6} \mathrm{PBMCs} / \mathrm{mL}$ after $12 \mathrm{~h}$. All co-cultures were established as Ad-MSC:PBMC and HeLa:PBMC cells with ratio of $1: 10$. For T cell stimulation, $5 \mu \mathrm{g} / \mathrm{mL}$ of PHA-M (Gibco) was used. Afterwards, cytokine assay was performed using ELISA on supernatant and quantitative real-time RT-PCR on PBMCs. As a normal controls, Ad-MSCs and HeLa were co-cultured with healthy donor
PBMCs. All culture sets were incubated in a saturated humidity incubator at $37{ }^{\circ} \mathrm{C}$ in the presence of $5 \% \mathrm{CO}_{2}$ for $24 \mathrm{~h}$. Then, PBMCs and their supernatants were collected by centrifugation and were stored separately at $-70{ }^{\circ} \mathrm{C}$ for further analysis.

\subsection{Detection of cytokine secretion}

The cytokine levels of IL-6, IL-17, IL-21, IL-23 and TGF- $\beta$ in the coculture supernatants and sera were measured and quantitated by enzyme linked immunosorbent assay (ELISA) kits according to the manufacture's instruction (eBiosciences, San Diego, CA, USA). Briefly, premixed standards were reconstituted in PBS ( $\mathrm{pH} 7.2$ ), to generate a stock concentration of 200,500, 4000, 2000 and $1000 \mathrm{pg} / \mathrm{mL}$ for IL-6, IL-17, IL-21, IL-23 and TGF- $\beta$, respectively. Diluted capture antibody was added to a 96-well, flat-bottomed, polystyrene microtiter plate. Plates were incubated overnight at room temperature, then washed with wash buffer. Premixed standards or samples $(100 \mu \mathrm{L})$ were added to each well, and incubated for overnight at $4{ }^{\circ} \mathrm{C}$. To activate latent TGF- $\beta$ to the immunoreactive form, the samples were acidified, and then neutralized. After incubation and washing, $100 \mu \mathrm{L}$ of the premixed detection antibody was added and incubated for $2 \mathrm{~h}$ at room temperature. After incubation and washing, Streptavidin-HRP was added to each well $(100 \mu \mathrm{L})$. The incubation was terminated after $20 \mathrm{~min}$ at room temperature and $50 \mu \mathrm{L}$ of stop solution was added to each well. Then optical density of each well was immediately determined using a microplate reader set at $450 \mathrm{~nm}$. The results were expressed in $\mathrm{pg} / \mathrm{mL}$ and $\mathrm{ng} / \mathrm{mL}$.

\subsection{RNA isolation and cDNA synthesis}

Total RNA was prepared from the blood cells after lysis with ammonium chloride and TRizol reagent (Invitrogen, Paisley, UK). For cDNA synthesis, RNA was treated with DNase I (Invitrogen-Gibco, Paisley, UK) to avoid DNA contamination, then cDNA was synthesized from 5
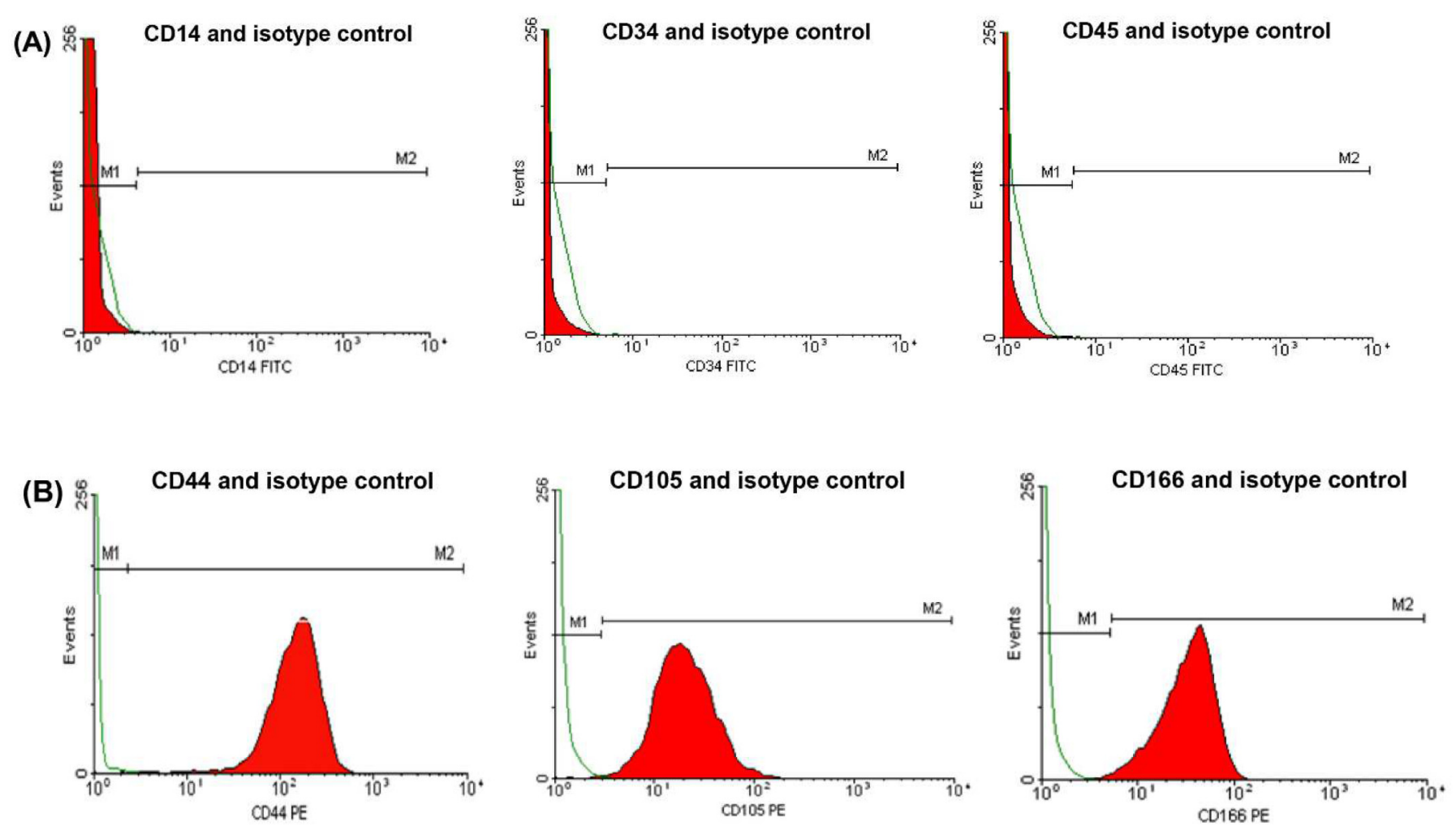

Fig. 1. Verification of Ad-MSCs. Surface expression of negative (CD14, CD34 and CD45) (A) and positive (CD44, CD105 and CD166) (B) markers on Ad-MSCs. 
$\mu \mathrm{g}$ of the total RNA using the First Strand cDNA Synthesis Kit (Applied Biosystems, Foster City, CA, USA).

\subsection{Quantitative real-time $R T-P C R$}

The abundance of IL-6, IL-17, IL-21, IL-23, and TGF- $\beta$ gene transcripts was determined by using the Step One Plus real-time PCR system (Applied Biosystems, Foster City, CA, USA) with SYBR Green PCR master mix kit (Applied Biosystems, Foster City, CA, USA). Expression of GAPDH housekeeping gene was used as a reference for the level of target gene expression. Each $\mathrm{PCR}$ reaction was performed in a final volume of $25 \mu \mathrm{L}$ and contained $0.5 \mu \mathrm{g}$ of the cDNA product, 4.0 pmol of each primer, and $1 \times$ reaction mixture, consisting of Fast Start DNA polymerase, reaction buffer, dNTPs, and SYBR green I. Table 2 shows the forward and reverse primers for genes. The primers were designed using primer 3 open-source software (Source forge, USA). Thermal cycling for all the
(A)

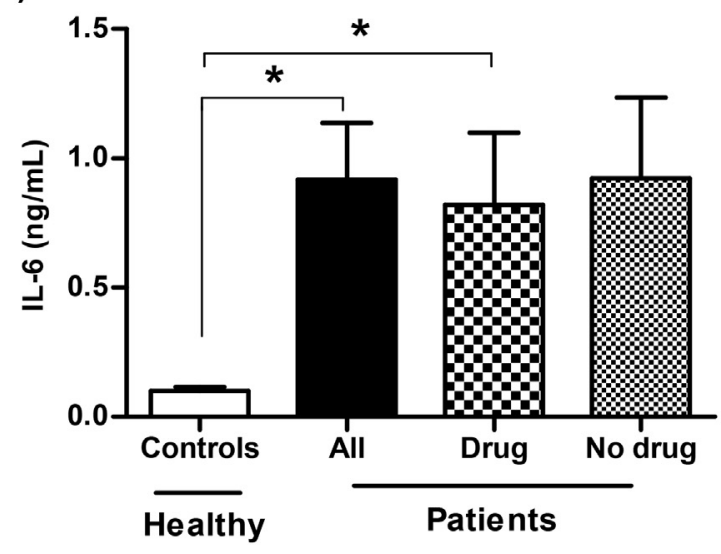

(C)

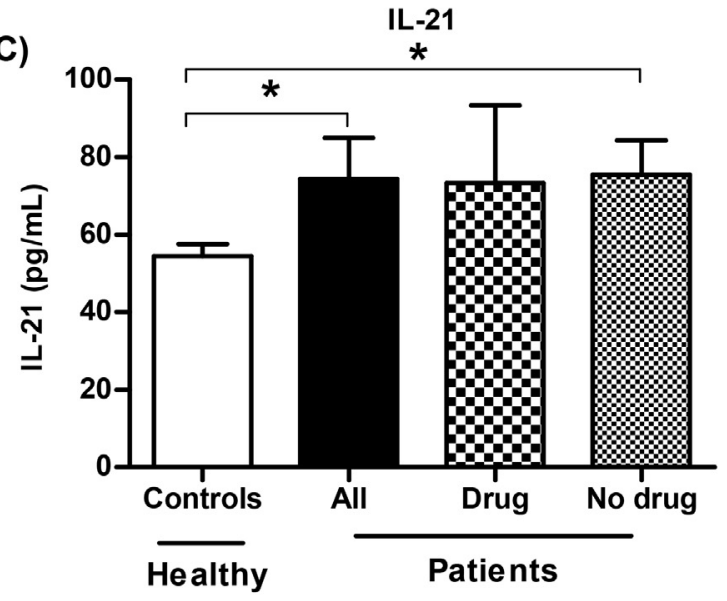

(E)

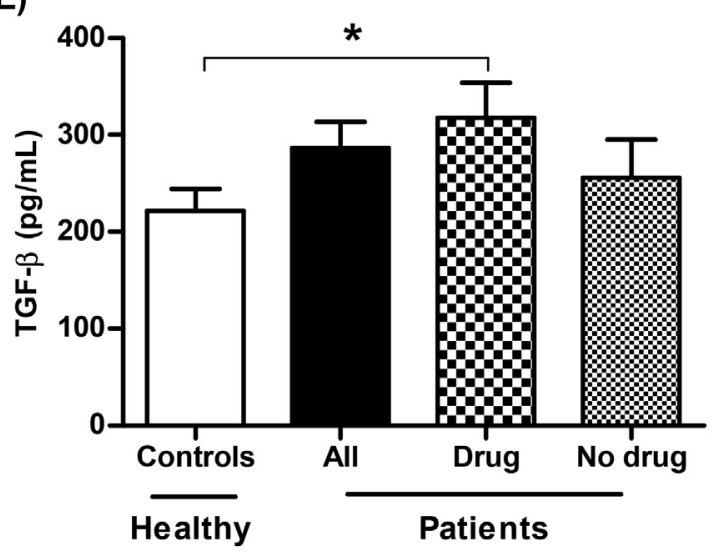

(B)

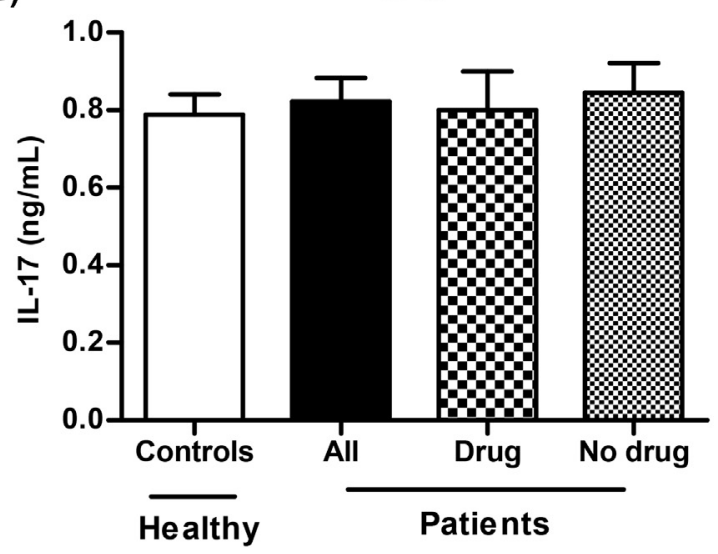

(D)

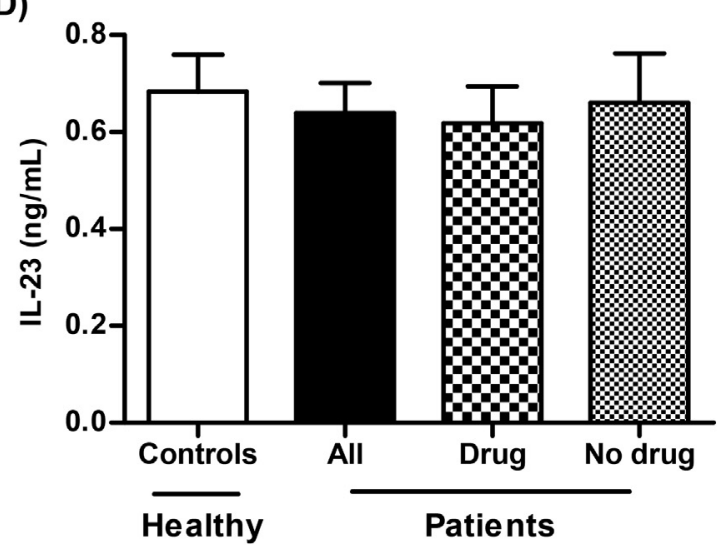

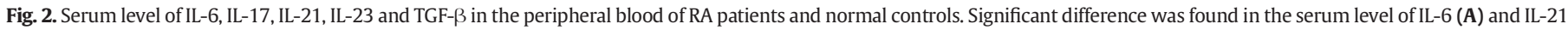

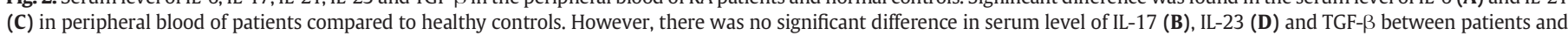
controls. Results were analyzed with the nonparametric two-tailed Mann-Whitney $U$ test. Values are the mean $\pm \mathrm{SEM} ;{ }^{*}=p<0.05$. 
genes was initiated with a denaturation step at $95^{\circ} \mathrm{C}$ for $1 \mathrm{~min}$, followed by 40 cycles (denaturation at $95^{\circ} \mathrm{C}$ for $10 \mathrm{~s}$, annealing at $56^{\circ} \mathrm{C}$ for $30 \mathrm{~s}$, and extension at $60{ }^{\circ} \mathrm{C}$ for $60 \mathrm{~s}$ when fluorescence appeared). The qRTPCR amplification products were analyzed by melting curve analysis. Meanwhile, all the data were analyzed for calibrated equipment.

\subsection{Statistical analysis}

Data were analyzed using nonparametric Kruskal-Wallis and MannWhitney $U$ tests by SPSS software v. 15 (SPSS, Chicago, IL, 173 USA). The relative amounts of cytokines transcripts were determined using $2^{-\Delta \Delta C t}$

\section{(A)}

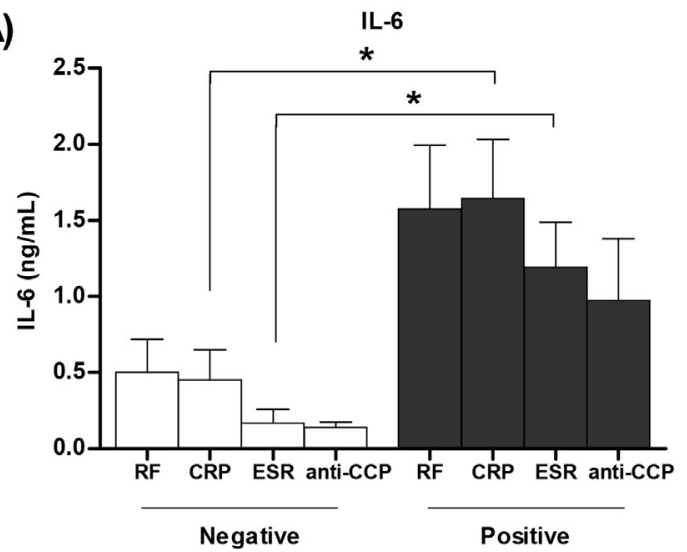

(C)

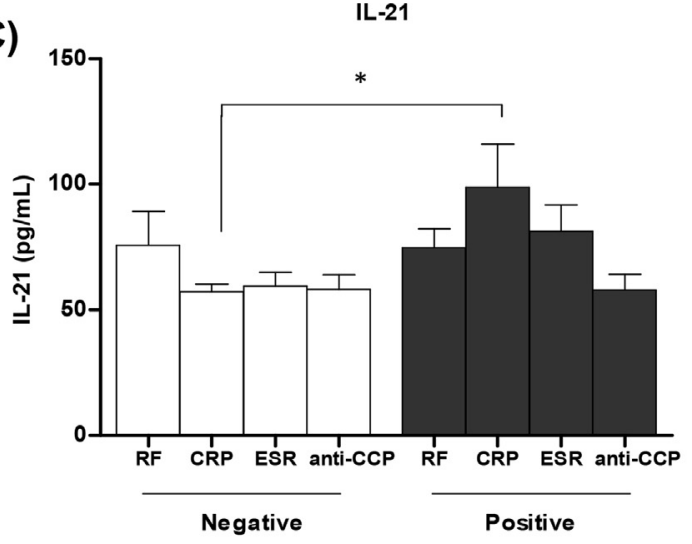

(E)

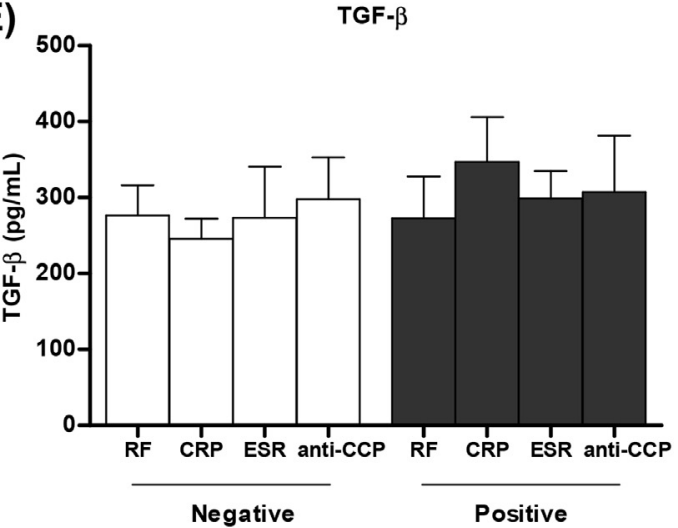

formula. Target-to-reference gene ratios were calculated with the Pfaffl method [24]. The variable levels were evaluated by means of Prism 5 software Inc. (San Diego CA, USA, 2003). $p<0.05$ was regarded as significant in all statistical analyses.

\section{Results}

\subsection{Verification of human Ad-MSCs population}

For verification of the Ad-MSCs, four- and fifth-passage cells were surface stained for negative and positive Ad-MSC markers and then

(B)

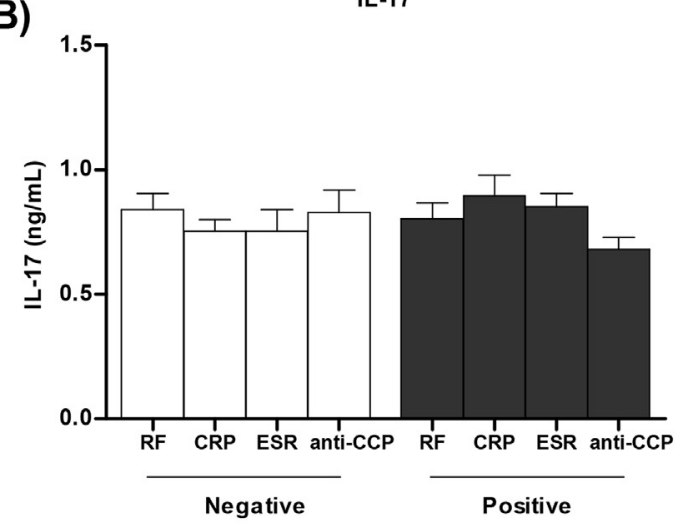

(D)

IL-23

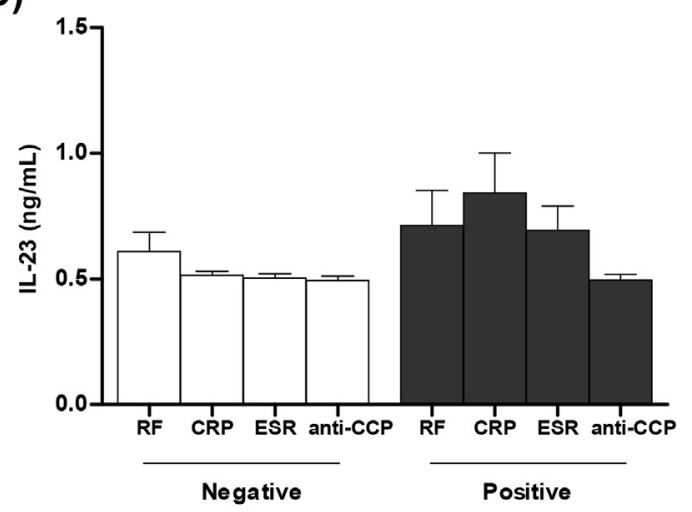

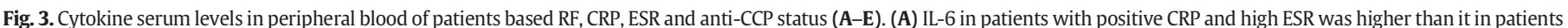

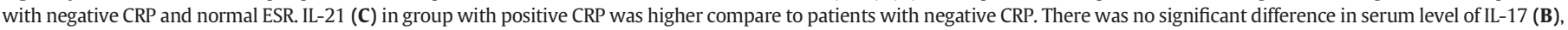

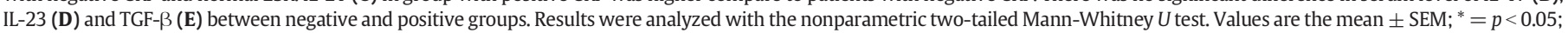
RF: Rheumatoid factor; CRP: C-reactive protein; ESR: Erythrocyte sedimentation rate; Anti-CCP: anti-cyclic citrullinated peptide. 
subjected to flow cytometric analysis. It was revealed that the cells were negative for hematopoietic markers CD14, CD34, and CD45 (Fig. 1A); and positive for Ad-MSC markers CD44, CD105, and CD166 (Fig. 1B). These results indicate that the cells retained the characteristics of stem cells.

\subsection{Cytokine assay in patient and healthy groups}

The serum level of IL-6, IL-17, IL-21, IL-23 and TGF- $\beta$ in patients with RA and normal controls was examined using ELISA method. It was shown that the serum level of IL-6 among all patients and patient group with immunosuppressive drugs significantly increased compared to controls (Fig. 2A). In addition, IL-6 among the patients with high ESR and positive CRP was higher than negative controls (Fig. 3A).

However, IL-17 level was similar in both patient and normal individuals (Fig. 2B) and levels of IL-17 were not significantly different between patients with inflammation and non-inflammation status (Fig. 3B).

As shown in Fig. 2C, specimens of all patients and patient group without drug usage had substantially higher level of IL-21 than control group. Also, patients with positive CRP had higher IL-21 serum level compared to patients with negative CRP (Fig. 3C).

Serum level of IL-23 (Fig. 2D) in patients with RA did not show difference when compared to the control group.

However, patients who were using immunosuppressive drugs showed higher TGF- $\beta$ compared to healthy controls (Fig. 2E). As shown in Figs. 3D and E, two noted cytokines had no significant difference between patients with inflammatory and non-inflammatory status.

3.3. Regulatory effect of Ad-MSCs on PBMCs through the reduced pro-inflammatory and increased anti-inflammatory cytokines

The effect of Ad-MSCs on the synthesis of IL-6, IL-17, IL-21, IL-23, and TGF- $\beta$ by activated PBMCs of patients with RA and healthy controls was assessed by ELISA and quantitative real-time PCR on supernatants and PBMCs co-cultured with Ad-MSCs and HeLa in the presence of PHA after $24 \mathrm{~h}$.

As shown, the Ad-MSCs inhibited IL-17 and IL-21 production in patient and control groups. Interestingly, TGF- $\beta$ expression by PBMCs in healthy controls was efficiently promoted.
(A)

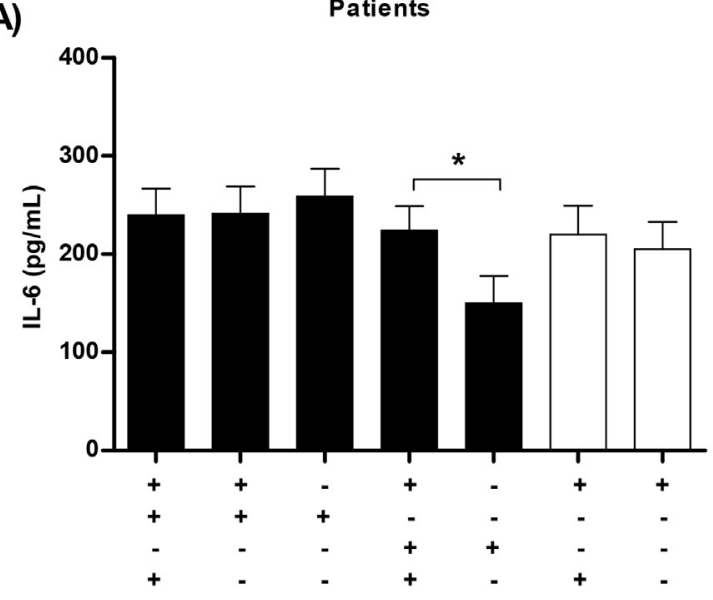

(B)

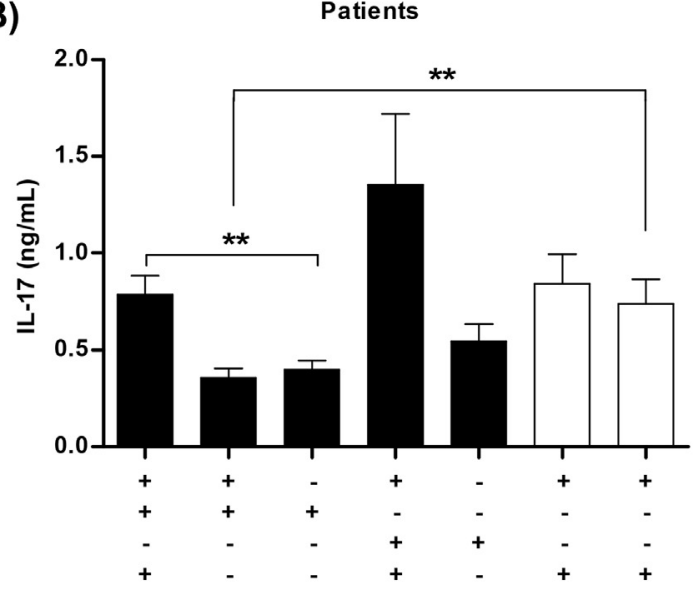

Controls
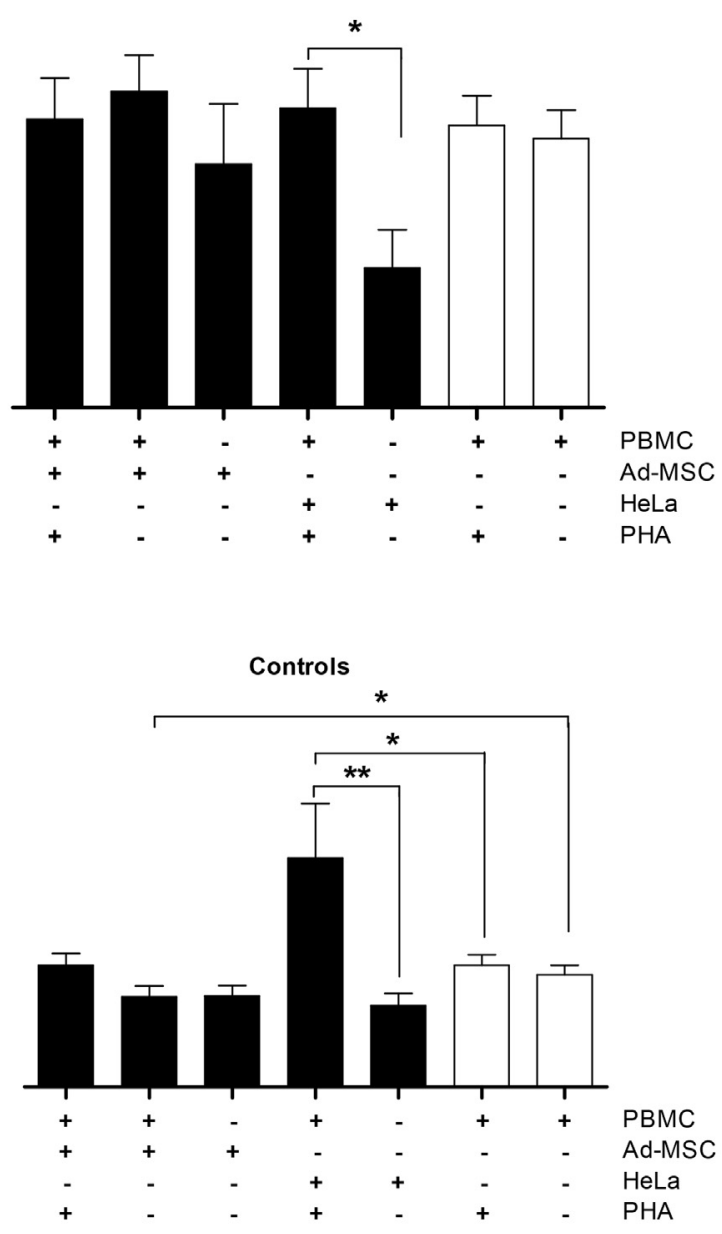

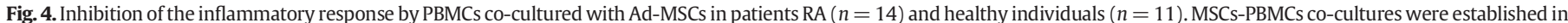

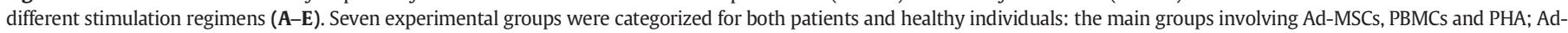

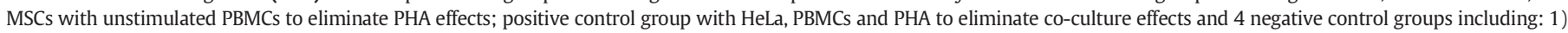

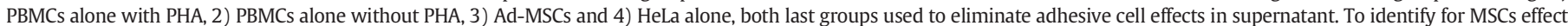

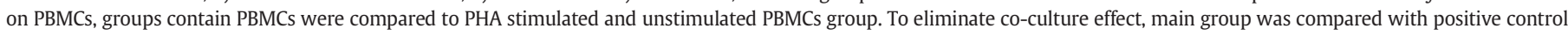

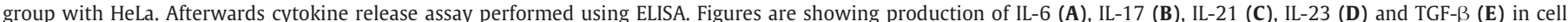

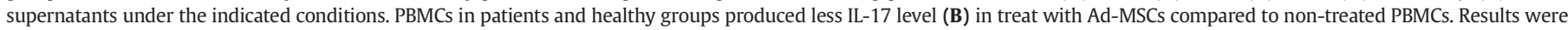

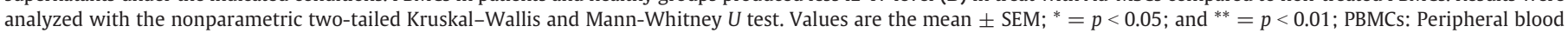
mononuclear cells; Ad-MSCs: Adipose tissue derived mesenchymal stem cells; PHA: Phytohaemagglutinin; RA: Rheumatoid arthritis. 
(C)

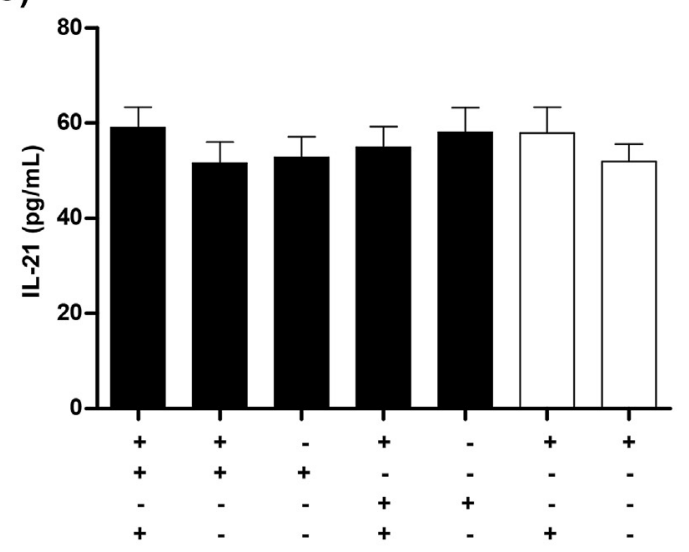

(D)

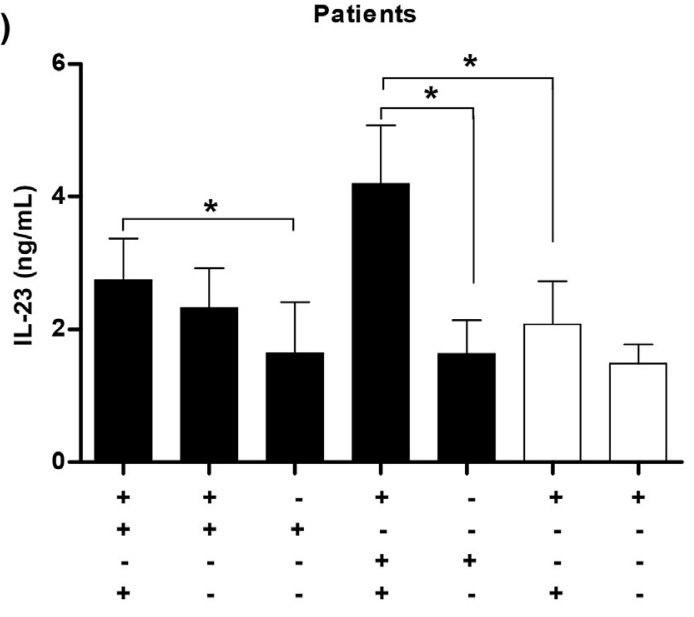

(E)

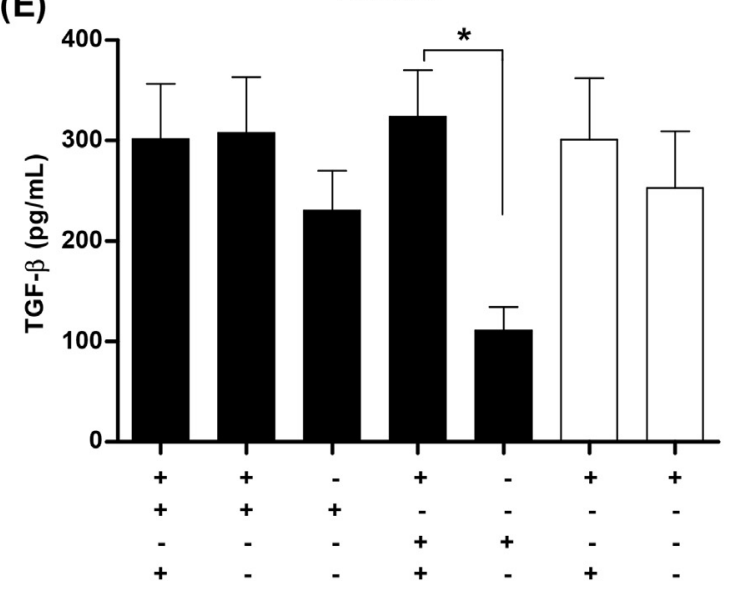

Controls
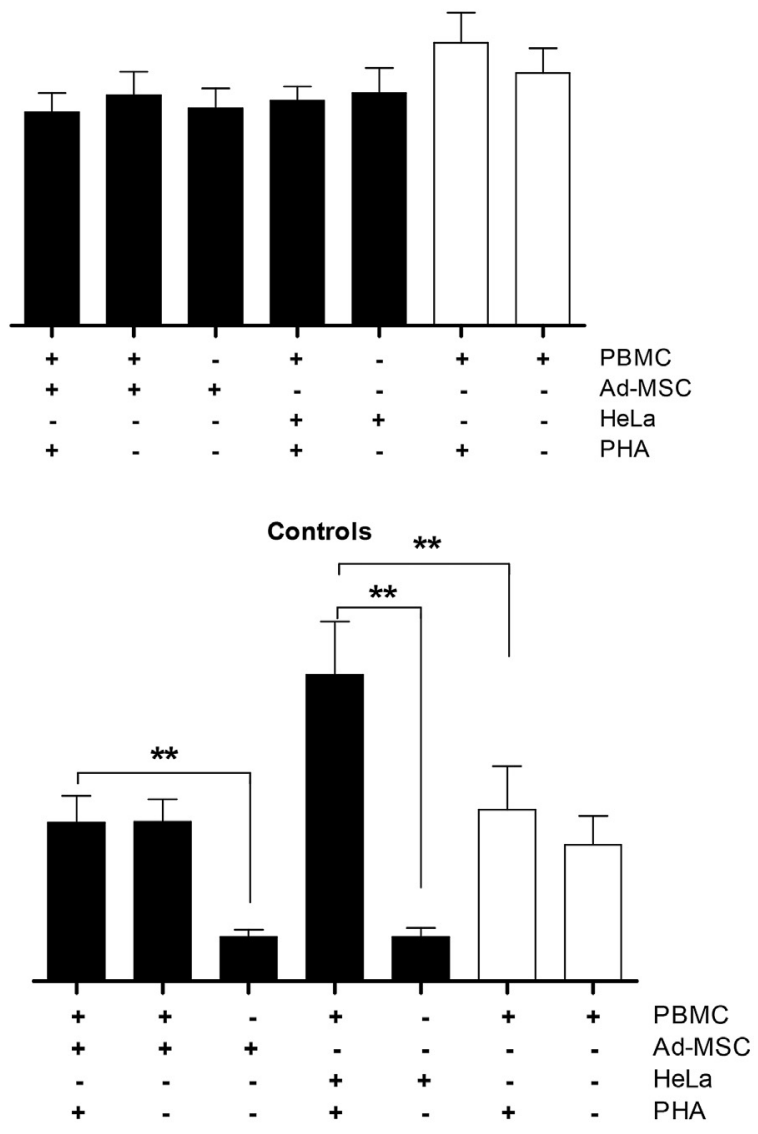

Controls

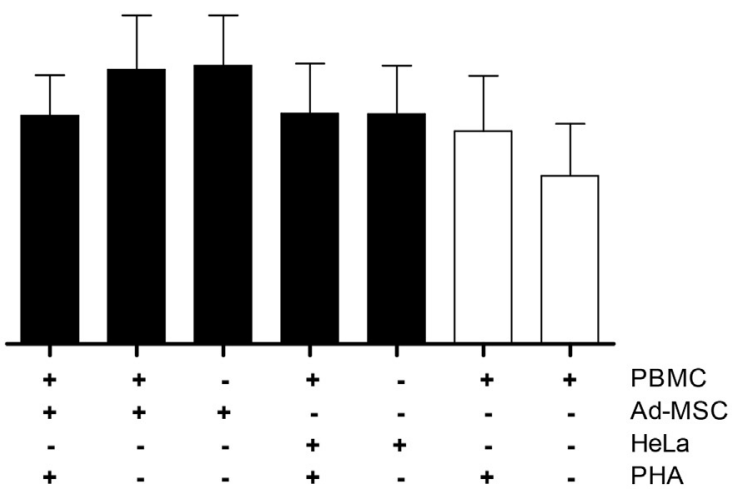

Fig. 4 (continued)

Supernatants of neither PHA-stimulated PBMCs nor non-stimulated PBMCs cultured with Ad-MSC revealed significant difference of IL-6 compared to PBMCs cultured alone as negative control (Fig. 4A). However, activated PBMCs cultured with HeLa produced more IL- 6 rather than HeLa cultured alone. In contrast, gene expression of IL-6 in unstimulated PBMCs cultured with Ad-MSC revealed difference compared to unstimulated PBMCs cultured alone as a negative control in patients' category. However, there was no statistically difference (Fig. 5A).
As shown in Fig. 4B, at a MSC-PBMC ratio of 1:10, Ad-MSCs inhibited PBMCs from IL-17 secretion compared to unstimulated PBMCs cultured in patient and healthy groups. It reveals that PHA-stimulated PBMCs treated with Ad-MSC produced more IL-17 compared to MSCs group. Further, the level of IL-17 was remarkably increased in the HeLa-treated group as control relative to the PHA-stimulated PBMCs- and HeLa-cultured alone groups in the healthy individuals (Fig. 4B). Compared to PHA-stimulated PBMCs cultured alone group, IL-17 expression of the 
PBMC-treated with Ad-MSCs and HeLa groups were similar in patient group. However, IL-17 expression in Ad-MSC:PBMCs without PHA group was less compared to unstimulated PBMCs among healthy group (Fig. 5B). Also, co-culture had no effect on IL-17 production in Hela-treated PBMCs compared to the MSC-treated group with PHA.

Although IL-21 levels of the PBMC-treated with Ad-MSCs groups had not any significant difference in both patient and healthy groups (Fig. 4C), Ad-MSCs inhibited IL-21 expression by PBMCs compared to unstimulated PBMCs cultured alone in patient group. In healthy controls, Ad-MSCs had inhibitory effect on IL-21 expression in MSC-treated PBMCs compared to PHA-stimulated and unstimulated PBMCs (Fig. 5C).

As shown in Fig. 4D levels of IL-23 in PBMC cultures from both of patient and healthy groups were unaffected by Ad-MSCs. Nevertheless, HeLa further increased IL-23 production by PBMCs compared to PHAstimulated PBMCs- and HeLa-cultured alone groups (Fig. 4D). In co-culture PBMCs with Ad-MSCs, IL-23 secretion was higher in co-culture groups rather than alone Ad-MSCs group as negative control. Unlike cytokine secretion, IL-23 expression in PBMCs from both patient and healthy groups were unaffected by Ad-MSCs (Fig. 5D).
To examine the anti-inflammatory effect of Ad-MSCs on the PBMCs of patient and healthy individuals, TGF- $\beta$ was assessed. There was no significant difference between all groups (Fig. 4E). TGF- $\beta$ expression, however, in healthy individuals was remarkably increased in both MSC-treated groups compared to PHA-stimulated and unstimulated PBMCs. Ad-MSC had no effect on TGF- $\beta$ production in patients (Fig. 5E).

\section{Discussion}

Human Ad-MSCs possess particular properties that make them appropriate to be used as a regenerative and immunomodulatory agent [25]. In RA, as an auto-inflammatory disease, pro-inflammatory cytokines such as TNF- $\alpha$, IL-6, IL-1 and IL-17 play dominant pathological roles, and also Th1 and Th17 cell subsets are well known to mediate inflammation in the pathogenesis of the disease $[11,12,26]$. Therefore, finding new agents which can affect cytokine production by these cell lineages may lead to a promising treatment for RA.

First, in this study, we evaluated the serum level of IL-17 as hallmarks of Th17 cells, as well as IL-6, IL-21 and TGF- $\beta$ levels as the
(A)

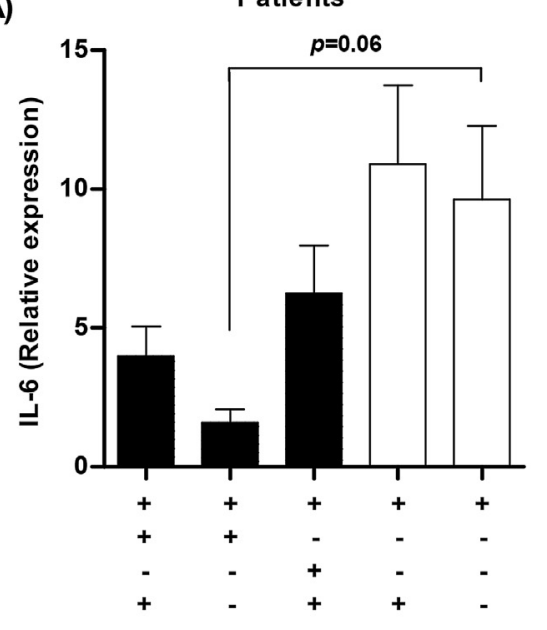

(B)

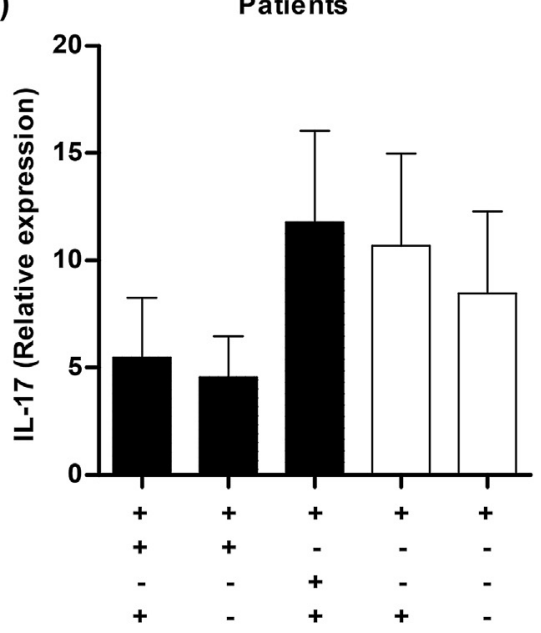

Controls

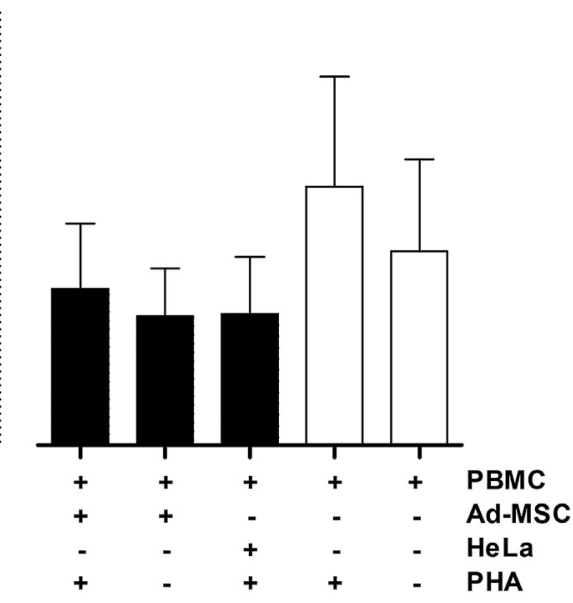

Controls

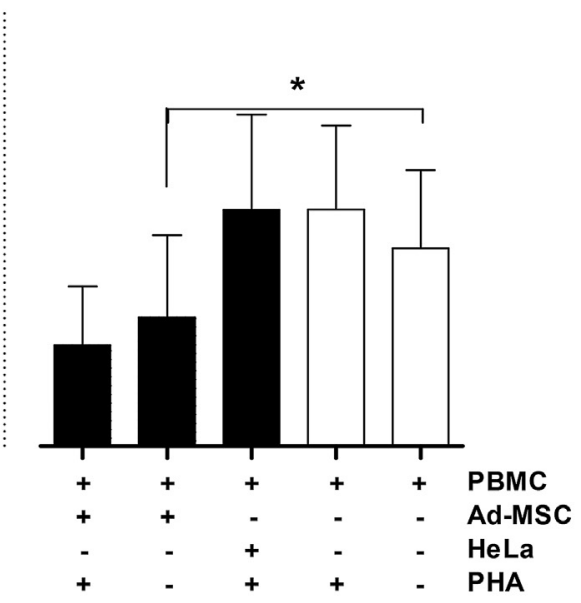

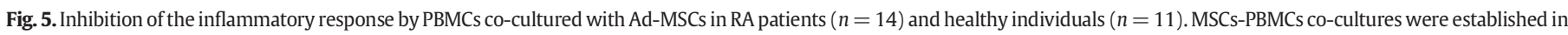

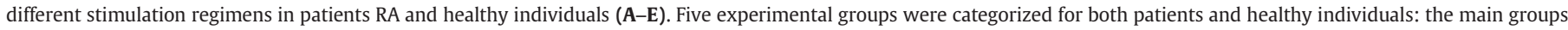

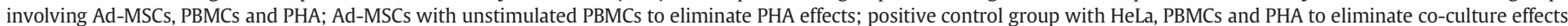

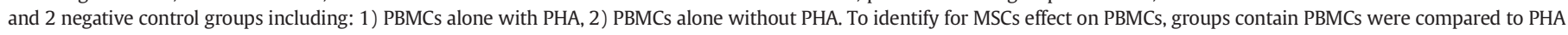

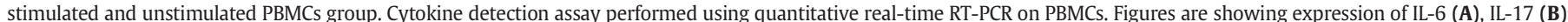

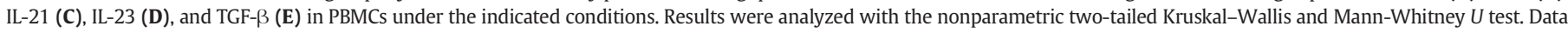

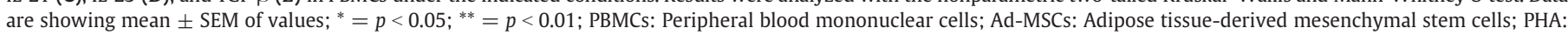
Phytohaemagglutinin; RA: Rheumatoid arthritis. 
(C)

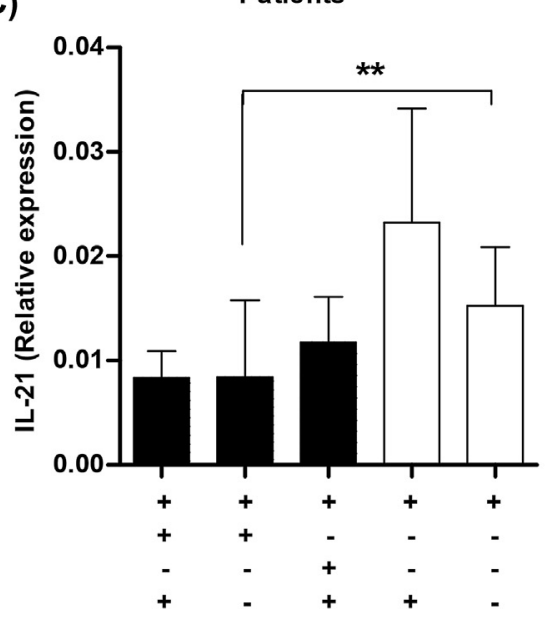

(D)

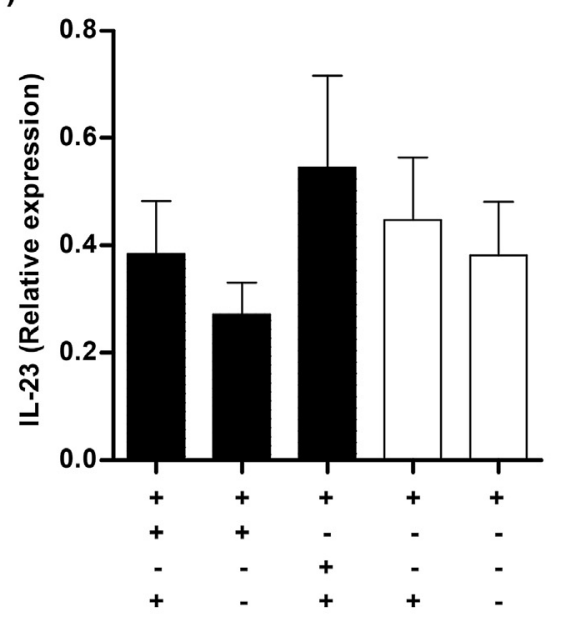

(E)

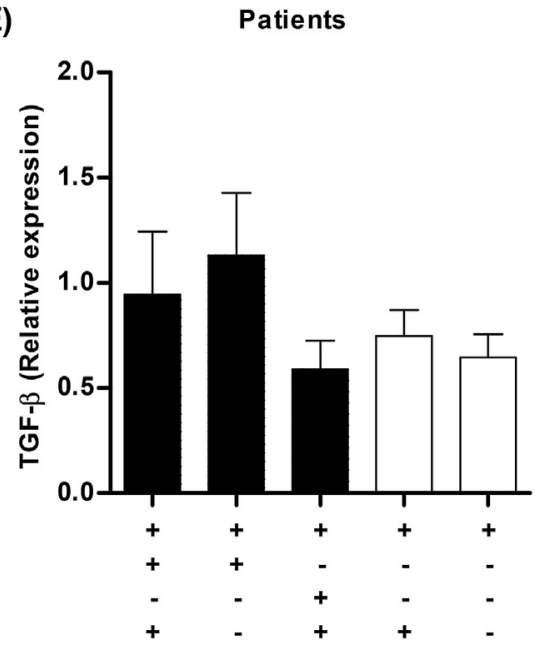

Controls

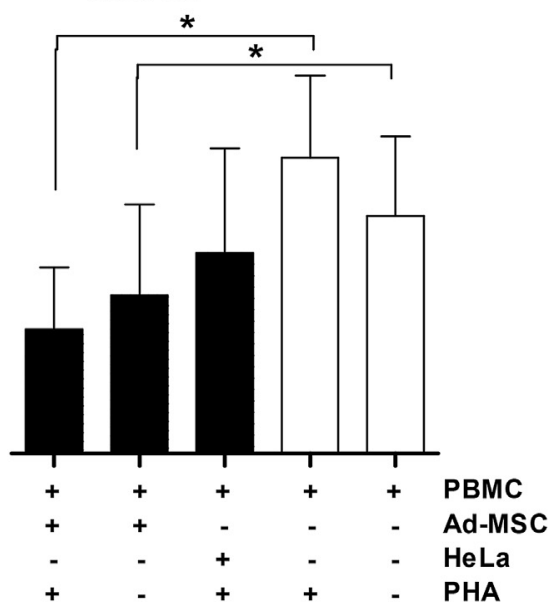

Controls
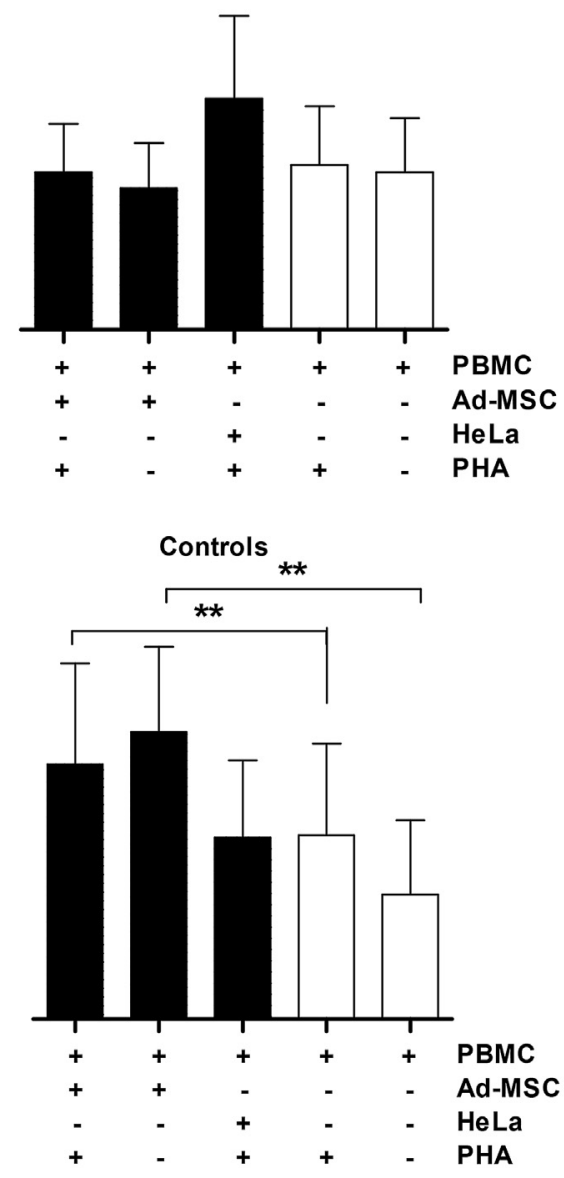

Fig. 5 (continued).

cytokines inducing Th17 cell differentiation, and also IL-23 as the maintaining cytokine for Th17 phenotype in peripheral blood mononuclear cells of patients with RA. Our data indicated a higher serum level of IL6 and IL-21 in patients compared to controls. In addition, IL- 6 level among the patients with high ESR and positive CRP and also IL-21 level among the patients with positive CRP, were higher than them in negative controls. We demonstrated that patients with RA had Th17- dependent inflammation especially IL-6, even though they had received corticosteroid and immune-suppressive drugs.

Since Ad-MSCs have provided a highly effective therapy for RA, strikingly reducing the two deleterious components of the disease, the autoimmune and inflammatory responses, we treated patients' PBMCs with Ad-MSCs. We observed that Ad-MSCs inhibited IL-6, IL-21 and IL-17 production and increased TGF- $\beta$ expression by PBMCs in comparison 
to PBMCs cultured alone. This finding was in accordance with some previous studies, such as Kim et al. and Zhou et al., which showed administration of hAd-MSCs in an animal model of arthritis reduced levels of pro-inflammatory cytokines including IL-6, IL-17, TNF- $\alpha$, and IFN- $\gamma$ $[20,27]$. In a previous study it was shown that when human MSCs were added in co-cultures with immune cells, the cytokine-secretion profile of dendritic cells, naive and effector Th1 and Th2, altered in favor of anti-inflammatory phenotypes [28]. Consistent with our findings, Ghannam et al. recently showed that MSCs inhibit the differentiation of naive T cells into Th17 cells [29] and Van Hamburg et al. showed that memory Th 17 cells can enhance their IL-17 production in the presence of stromal cells [30].

In an attempt to augment the therapeutic efficacy of Ad-MSCs in suppressing RA, we compared Ad-MSCs effects with another adherent cell-HeLa effects in order to eliminate co-culture effects. Compared with Ad-MSCs, HeLa cell line exerted more potent proliferative and inflammatory activity and induced Th17-associated cytokines production in vitro. These data suggest that whole changes in anti-inflammatory profile is due to Ad-MSCs effects, but not co-culture. We demonstrated that compared with PHA-stimulated PBMCs, unstimulated PBMCs had no change in cytokine secretion profile. Our results demonstrated that PHA had no interfering effect on anti-inflammatory function of AdMSCs.

A recent study by Wang et al. also showed that IL- 6 and TNF- $\alpha$ were declined after treatment of juvenile idiopathic arthritis (JIA) patients by umbilical cord mesenchymal stem cells (UC-MSCs) [31]. Over the past few years, studies have shown that patients with RA have high concentrations of IL-21 and IL-22. IL-21 auto-regulates its own production in human $\mathrm{CD} 4^{+} \mathrm{T}$ cells, promotes Th17 proliferation and is strongly associated with levels of autoantibodies and disease severity. In addition, IL- 6 together with TGF- $\beta$ is the key inducer of Th17 cells via activation of transcription-3 (STAT3), and its level is significantly associated with clinical symptoms [32].

However, in the present study, there was no significant difference in IL-23 gene expressions and secretion in the PBMC-treated with AdMSCs in both patient and healthy groups, it is assumed if there was more enough sample size, the difference in patient group was probably statistically significant. Consistent with our findings Crop et al. showed that immunosuppressive capacity of MSCs was enhanced strongly under inflammatory conditions. Actually culture of MSCs with alloactivated lymphocytes or pro-inflammatory cytokines affected MSCs morphology, proliferation and gene expression of cytokines, chemokines and HLA molecules. These gene expression changes led to increased immunosuppressive capacity of Ad-MSCs [33]. Culture of Ad-MSCs with PBMCs improved the capacity of MSC to inhibit the proliferation of mitogen or alloantigen stimulated lymphocytes. Culture of Ad-MSCs with pro-inflammatory cytokines enhanced the immunosuppressive capacity of Ad-MSCs even further. In accordance with some previous studies our findings suggest that the more intensive immunosuppressive effects of Ad-MSCs on PBMCs of patients with RA is due to inflammatory condition of patients with RA. Despite the fact that some RA patients were receiving immunosuppressive drug, inflammation was more dominant in them compared to healthy individuals.

Although the present study showed that Ad-MSC had no effect on TGF- $\beta$ production in the patient group, gene expression of this cytokine in healthy individuals remarkably increased in the both MSC-treated groups with and without PHA. Consistent with our findings, Mohammadzadeh's study indicated that Ad-MSCs greatly impact the up-regulation of TGF- $\beta$ in C57BL/6 spleen-isolated mononuclear cells [34]. In addition, Kim et al. and Zhou et al. showed that administration of Ad-MSCs in mice increased levels of TGF- $\beta$ and IL-10 (20, 27), whereas Gonzalez-Rey et al. showed that TGF- $\beta$ was not significantly increased in the co-cultures of hAd-MSCs and PBMCs in patients. In addition, TGF- $\beta$ blockade had no remarkable effect on the immunomodulatory functions of hAd-MSCs which suggested that hAd-MSCs could act via different inhibitory mechanisms [35].
One study evaluated the effect of human allogeneic Ad-MSCs on collagen-reactive $\mathrm{T}$ cells isolated from RA patients in vitro. These cells prevented proliferation and pro-inflammatory cytokine expression of collagen-activated $\mathrm{T}$ cells, while an increase in the number of IL-10 producing $T$ cells was observed [35].

It seems Ad-MSCs in co-culture with PBMCs of patient with inflammatory status induce a surge in pro-inflammatory cytokines production by activated PBMCs at early stages of their interaction. Then, they become more potent for suppression of Th17 activation. These results similar to Del Fattore's findings [36] suggest that MSCs in patients rather than controls induce a transient proinflammation by T cells. But after immune suppressive molecules expression by MSCs such as IDO that block T-cell proliferation, IL-17 production was reduced.

Some differences between gene expression and cytokine secretion in present study suggest that while for some cytokines expression levels closely mirror protein levels (IL-17), for other factors this is not the case. The imperfect and variable correlation between mRNA and protein levels is in agreement with previous reports [37] and can be explained by post-transcriptional and post-translational regulation and by misclassification due to measurement errors.

In accordance with these findings, the results showed that Ad-MSCs suppress the production of pro-inflammatory cytokines such as IL-6, IL17 and IL-21 which have important roles in the pathogenesis of the rheumatoid arthritis. Also, they have a high capacity to induce TGF- $\beta$ production by lymphocytes. The capacity of human Ad-MSCs to regulate a wide spectrum of inflammatory mediators, together with the suppression of Th17 responses, might offer a therapeutic advantage for AdMSCs over the neutralizing antibodies directed against a single mediator. In addition, it seems Ad-MSC therapy along with conventional treatment by immunosuppressive drugs can result in better responses to treatment of autoimmune arthritis or other T cell-mediated autoimmune diseases.

\section{Conflict of interest}

The authors declare that they have no conflict of interests.

\section{Acknowledgements}

The authors thank the patients with rheumatoid arthritis as well as the normal individuals for their kind participation in this project. This work was financially supported by a grant from Iran National Science Foundation (INSF) (Grant No. 90005754) and Jahrom University of Medical Sciences (Grant No. 90-4867).

\section{References}

[1] J.K. Fraser, I. Wulur, Z. Alfonso, M.H. Hedrick, Fat tissue: an underappreciated source of stem cells for biotechnology, Trends Biotechnol. 24 (4) (2006) 150-154.

[2] F. Schena, C. Gambini, A. Gregorio, M. Mosconi, D. Reverberi, M. Gattorno, et al., Interferon- $\gamma$-dependent inhibition of B cell activation by bone marrow-derived mesenchymal stem cells in a murine model of systemic lupus erythematosus, Arthritis Rheum. 62 (9) (2010) 2776-2786.

[3] G.M. Spaggiari, A. Capobianco, H. Abdelrazik, F. Becchetti, M.C. Mingari, L. Moretta Mesenchymal stem cells inhibit natural killer-cell proliferation, cytotoxicity, and cytokine production: role of indoleamine 2, 3-dioxygenase and prostaglandin E2, Blood 111 (3) (2008) 1327-1333.

[4] F. Djouad, L.M. Charbonnier, C. Bouff, P. Louis-Plence, C. Bony, F. Apparailly, et al., Mesenchymal stem cells inhibit the differentiation of dendritic cells through an interleukin-6-dependent mechanism, Stem Cells 25 (8) (2007) 2025-2032.

[5] J.J. El-Jawhari, Y.M. El-Sherbiny, E.A. Jones, D. Mcgonagle, Mesenchymal stem cells, autoimmunity and rheumatoid arthritis, QJM (2014), hcu033.

[6] R.J. MacFarlane, S.M. Graham, P.S. Davies, N. Korres, H. Tsouchnica, M. Heliotis, et al. Anti-inflammatory role and immunomodulation of mesenchymal stem cells in systemic joint diseases: potential for treatment, Expert Opin. Ther. Targets 17 (3) (2013) 243-254.

[7] H.K. Lee, S.H. Lim, I.S. Chung, Y. Park, M.J. Park, J.Y. Kim, et al., Preclinical efficacy and mechanisms of mesenchymal stem cells in animal models of autoimmune diseases, Immune Netw. 14 (2) (2014) 81-88.

[8] K. English, J. Ryan, L. Tobin, M. Murphy, F. Barry, B. Mahon, Cell contact, prostaglandin E2 and transforming growth factor beta 1 play non-redundant roles in human 
mesenchymal stem cell induction of CD4 + CD25Highforkhead box P3 + regulatory T cells, Clin. Exp. Immunol. 156 (1) (2009) 149-160.

[9] A. Tyndall, Successes and failures of stem cell transplantation in autoimmune diseases, ASH Education Program Book 2011 (1) (2011) 280-284.

[10] D. Kyburz, A. Finckh, The importance of early treatment for the prognosis of rheumatoid arthritis, Swiss Med. Wkly. 143 (2013), w13865.

[11] E.Y. Chiang, G.A. Kolumam, X. Yu, M. Francesco, S. Ivelja, I. Peng, et al., Targeted depletion of lymphotoxin- $\alpha$-expressing $\mathrm{TH} 1$ and $\mathrm{TH} 17$ cells inhibits autoimmune disease, Nat. Med. 15 (7) (2009) 766-773.

[12] E. Gonzalez-Rey, A. Chorny, N. Varela, F. O'Valle, M. Delgado, Therapeutic effect of urocortin on collagen-induced arthritis by down-regulation of inflammatory and Th1 responses and induction of regulatory T cells, Arthritis Rheum. 56 (2) (2007) 531-543.

[13] M. Jaberipour, R. Baharlou, A. Hosseini, A. Talei, M. Razmkhah, A. Ghaderi, Increased il-17 and il-6 transcripts in peripheral blood mononuclear cells: implication for a robust proinflammatory response in early stages of breast cancer, Middle East J. Cancer 2 (1) (2011) 19-26.

[14] M.R. Ehrenstein, J.G. Evans, A. Singh, S. Moore, G. Warnes, D.A. Isenberg, et al., Compromised function of regulatory T cells in rheumatoid arthritis and reversal by antiTNF $\alpha$ therapy, J. Exp. Med. 200 (3) (2004) 277-285.

[15] M.E. Morgan, R.P. Sutmuller, H.J. Witteveen, L.M. van Duivenvoorde, E. Zanelli, C.J. Melief, et al., CD25 + cell depletion hastens the onset of severe disease in collagen-induced arthritis, Arthritis Rheum. 48 (5) (2003) 1452-1460.

[16] M. Van Oosterhout, E. Levarht, J. Sont, T. Huizinga, R. Toes, J. Van Laar, Clinical efficacy of infliximab plus methotrexate in DMARD naive and DMARD refractory rheumatoid arthritis is associated with decreased synovial expression of TNF $\alpha$ and IL18 but not CXCL12, Ann. Rheum. Dis. 64 (4) (2005) 537-543.

[17] M. Nakou, G. Katsikas, P. Sidiropoulos, G. Bertsias, E. Papadimitraki, A. Raptopoulou, et al., Rituximab therapy reduces activated B-cells both in the peripheral blood and bone marrow of patients with rheumatoid arthritis: depletion of memory B-cells correlates with clinical response, Arthritis Res. Ther. 11 (4) (2009) R131.

[18] K.L. Hyrich, D.P. Symmons, K.D. Watson, A.J. Silman, Comparison of the response to infliximab or etanercept monotherapy with the response to cotherapy with methotrexate or another disease-modifying antirheumatic drug in patients with rheumatoid arthritis: results from the British Society for Rheumatology Biologics Register Arthritis Rheum. 54 (6) (2006) 1786-1794

[19] J. Listing, A. Strangfeld, R. Rau, J. Kekow, E. Gromnica-Ihle, T. Klopsch, et al., Clinical and functional remission: even though biologics are superior to conventional DMARDs overall success rates remain low-results from RABBIT, the German biologics register, Arthritis Res. Ther. 8 (3) (2006) R66.

[20] B. Zhou, J. Yuan, Y. Zhou, M. Ghawji, Y.-P. Deng, A.J. Lee, et al., Administering human adipose-derived mesenchymal stem cells to prevent and treat experimental arthritis, Clin. Immunol. 141 (3) (2011) 328-337.

[21] R. Maccario, M. Podestà, A. Moretta, A. Cometa, P. Comoli, D. Montagna, et al., Interaction of human mesenchymal stem cells with cells involved in alloantigen-specific immune response favors the differentiation of CD4 + T-cell subsets expressing a regulatory/suppressive phenotype, Haematologica 90 (4) (2005) 516-525.

[22] Y. Liu, R. Mu, S. Wang, L. Long, X. Liu, R. Li, et al., Therapeutic potential of human umbilical cord mesenchymal stem cells in the treatment of rheumatoid arthritis, Arthritis Res. Ther. 12 (6) (2010) R210.
[23] W.-J. Lee, Y.-S. Hah, S.-A. Ock, J--H. Lee, R.-H. Jeon, J.-S. Park, et al., Cell source-dependent in vivo immunosuppressive properties of mesenchymal stem cells derived from the bone marrow and synovial fluid of minipigs, Exp. Cell Res. 333 (2) (2015) 273-288.

[24] M.W. Pfaffl, A new mathematical model for relative quantification in real-time RTPCR, Nucleic Acids Res. 29 (9) (2001), e45-e.

[25] M. Roemeling-van Rhijn, F.K. Mensah, S.S. Korevaar, M.J. Leijs, G.J. Van Osch, J.N. IJzermans, et al., Effects of hypoxia on the immunomodulatory properties of adipose tissue-derived mesenchymal stem cells, Front. Immunol. 4 (2013).

[26] R. Baharlou, A. Ahmadi-Vasmehjani, M.H. Davami, F. Faraji, M.R. Atashzar, F. Karimipour, et al., Elevated levels of T-helper 17-associated cytokines in diabetes type I patients: indicators for following the course of disease, Immunol. Investig. 45 (7) (2016) 641-651.

[27] J.-H. Kim, Y.T. Lee, K. Oh, J. Cho, D.-S. Lee, Y.-I. Hwang, Paradoxical effects of human adipose tissue-derived mesenchymal stem cells on progression of experimental arthritis in SKG mice, Cell. Immunol. 292 (1) (2014) 94-101.

[28] S. Aggarwal, M.F. Pittenger, Human mesenchymal stem cells modulate allogeneic immune cell responses, Blood 105 (4) (2005) 1815-1822.

[29] S. Ghannam, J. Pène, G. Torcy-Moquet, C. Jorgensen, H. Yssel, Mesenchymal stem cells inhibit human Th17 cell differentiation and function and induce a T regulatory cell phenotype, J. Immunol. 185 (1) (2010) 302-312.

[30] J. Van Hamburg. P. Asmawidjaja, N. Davelaar, A. Mus, E. Colin, J. Hazes, et al., Th17 cells, but not Th1 cells, from patients with early rheumatoid arthritis are potent inducers of matrix metalloproteinases and proinflammatory cytokines upon synovial fibroblast interaction, including autocrine interleukin-17A production, Arthritis Rheum. 63 (1) (2011) 73-83.

[31] L. Wang, Y. Zhang, H. Li, J. Hong, X. Chen, M. Li, et al., Clinical observation of employment of umbilical cord derived mesenchymal stem cell for juvenile idiopathic arthritis therapy, Stem Cells Int. 2016 (2015).

[32] X. Niu, G. Chen, Clinical biomarkers and pathogenic-related cytokines in rheumatoid arthritis, J. Immunol. Res. 2014 (2014).

[33] M. Crop, C. Baan, S. Korevaar, J. Ijzermans, M. Pescatori, A. Stubbs, et al., Inflammatory conditions affect gene expression and function of human adipose tissue-derived mesenchymal stem cells, Clin. Exp. Immunol. 162 (3) (2010) 474-486.

[34] A. Mohammadzadeh, A.A. Pourfathollah, S. Shahrokhi, S.M. Hashemi, S.L.A. Moradi, M. Soleimani, Immunomodulatory effects of adipose-derived mesenchymal stem cells on the gene expression of major transcription factors of T cell subsets, Int. Immunopharmacol. 20 (2) (2014) 316-321.

[35] E. Gonzalez-Rey, M.A. Gonzalez, N. Varela, F. O'Valle, P. Hernandez-Cortes, L. Rico, et al., Human adipose-derived mesenchymal stem cells reduce inflammatory and $\mathrm{T}$ cell responses and induce regulatory T cells in vitro in rheumatoid arthritis, Ann. Rheum. Dis. 69 (01) (2010) 241-248.

[36] A. Del Fattore, R. Luciano, L. Pascucci, B.M. Goffredo, E. Giorda, M. Scapaticci, et al., CT-1317 Accepted 02/12/2015 for Publication in "Cell Transplantation", 2015.

[37] Q. Tian, S.B. Stepaniants, M. Mao, L. Weng, M.C. Feetham, M.J. Doyle, et al., Integrated genomic and proteomic analyses of gene expression in mammalian cells, Mol. Cell. Proteomics 3 (10) (2004) 960-969. 